\title{
Anterior instrumentation for cervical spine tuberculosis: An analysis of surgical experience with 61 cases
}

\author{
Premanand S. Ramani, Alok Sharma*, Sunil Jituri, Dattatraya P. Muzumdar \\ Departments of Neuro and Spinal Surgery, Lilavati Hospital and Research Centre, Bandra (West), *Lokmanya Tilak Municipal College and \\ Hospital, Sion, Mumbai, India
}

Objective: To evaluate the efficacy of anterior instrumentation in patients with subaxial and cervicodorsal spinal tuberculosis in reconstruction of the spine, providing pain relief, neurological recovery and prevention of deformity. Materials and Methods: The records of 61 consecutive patients, of surgically treated spinal tuberculosis affecting C3 to D2 region, in our neuro and spinal surgery unit over a five-year period were retrospectively reviewed. Patients with involvement of the C3-C6 vertebrae underwent excision of the involved vertebrae and intervertebral discs followed by reconstruction with titanium implants by anterior approach. A transclavicular approach was used for patients with involvement of the C7-D2 vertebrae. A five-drug antituberculous regimen was administered for a period of one year. The follow-up ranged from 24 to 84 months (mean 38 months). Clinical and radiological assessment using flexion and extension radiographs was performed at 24 months for all cases. Results: The neck pain score based on a visual analog scale (1-10) changed from a pre-operative average of 7 to 2 at follow-up after 4 months. Fifty-two patients (85\%) had complete relief of pain while 16 patients who had Grade III to IV muscle strength regained complete power. The asymmetric wasting in patients with involvement of the cervicodorsal region did not recover completely. Flexionextension radiographs at 24 months did not show any evidence of instability or nonunion. Conclusions: Anterior reconstruction using titanium plates and locking screws for stabilization of the subaxial and cervicodorsal region tuberculosis is a useful adjunct in preventing kyphotic deformity. A satisfactory segmental stability and fusion is achieved by this technique.

Key Words: Anterior instrumentation, cervical spine tuberculosis, titanium implants

\section{Introduction}

The major concern with spinal tuberculosis includes spinal deformity and neurological impairment. ${ }^{[1-5]}$ Decompression of neural tissue followed by correction of spinal deformity with implants, under cover of chemotherapy, has been shown to relieve pain, improve neurological impairment and prevent deformity. Anterior instrumentation for tuberculosis of thoracic and thoracolumbar spine has been well described in the literature. ${ }^{[5-24]}$ We report our experience with anterior instrumentation using titanium implants for subaxial and cervicodorsal region tuberculosis in 61 patients.

\section{Materials and Methods}

During the period 1996 to 2000 , a total of 61 cases of spinal tuberculosis involving the subaxial and the cervicodorsal region underwent anterior instrumentation using titanium plates in our institution. The clinical notes, radiological images, operative records and follow-up data of patients were studied. The median age was 32 years (range 7 to 68 yrs.). The manual muscle testing of the patients was performed according to the Medical Research Council of United Kingdom. The indication for surgery was to relieve pain, improve neurological impairment and prevent spinal deformity.

Subaxial cervical spine: In this group, there were 44 females and 9 males. Their age ranged from 29 to 52 years (median age 38 yrs.) They presented with neck pain, difficulty in swallowing, weakness in upper limbs and myelopathy. One patient had muscle power < Grade III while 16 patients presented with power more than Grade III. Four patients had unilateral weakness in the small muscles of the hand and biceps humoris, three patients had deltoid muscle weakness and one patient with C3 involvement had right upper limb monoplegia. The remaining 28 patients had no neurological deficit. Onset of neck pain was assumed to be the initiation of the disease and patients had neck pain for as long as 24 months before presentation. 
Cervicodorsal region: In this group, 8 patients (all males) had significant neurological deficit. Four patients had power of $<$ Grade III and were bedridden. One patient had marked spasticity and flexor spasms while another developed hoarseness of voice. In this group, gross neurological deficit was the presenting symptom; whereas pain was the commonest symptom in the cervical group. The duration between onset of symptoms and presentation varied from 8 to 22 months.

Routine hematology investigations included an erythrocyte sedimentation rate (ESR). All patients were evaluated with plain radiography, magnetic resonance imaging (MRI) and in select cases, computerized tomography (CT). The destruction of the vertebrae and dises was easily identified in both sagittal and axial planes. The peripheral margins were exclusively enhanced in all cases. In most patients involvement of both anterior columns was noted (Figure 1a). There was bone destruction but no significant kyphotic deformity. Contrast-enhanced MRI was highly accurate in distinguishing granulation tissue from cold abscess. In our series, $80 \%$ of the patients had an atypical presentation with involvement of the vertebra, preservation of disc space and prevertebral abscess formation. The typical Pott's spine presentation was seen only in $20 \%$ of the patients. In one case who presented early (4 months) with neck pain, muscle spasm and restricted neck movements, diagnosis was established by axial CT scan cuts which showed a small area of destruction of bone subchondrally (Figure 1b). The diagnosis was later confirmed histologically. Preoperative skull traction was not used in any patient since there was no marked bone destruction or kyphosis.

In the lower cervical spine, the destruction was more prominent anteriorly in the vertebral body. The destroyed bone was adequately excised by an anterior approach. The procedure involved corpectomy of one or two vertebrae and excision of the intervening discs. When the disease was more confined, partial excision of the vertebra with the intervertebral disc was found to be adequate. The neural tissue was decompressed and stabilization was then carried out. The cervicodorsal junction was approached anteriorly with an incision 1 $\mathrm{cm}$ above and parallel to the clavicle. The insertion of one sternocleidomastoid muscle was detached subperiosteally. The sternohyoid and sternothyroid strap muscles were detached on the same side. The medial third of the clavicle was excised if necessary. The length and the thickness of the neck of the patient as well as the need for an

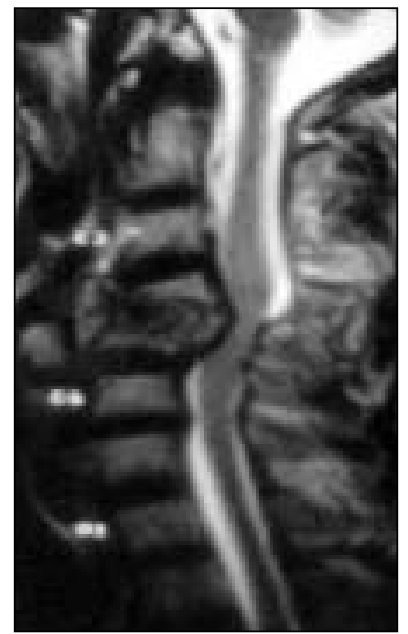

Figure 1a: Sagittal $T_{2}$-weighted MRI showing atypical tuberculosis of the cervical spine involving $\mathrm{C} 4$ vertebral body enhanced exposure dictated the need for a clavicular resection.

Following decompression, reconstruction was carried out using synthetic grafts like expandable cages $(n=9)$, titanium spacers filled with ceramic bone $(n=12)$ (Figure 2$)$ and Synthes plate with locking 12 or $14 \mathrm{~mm}$ screws [ $\mathrm{n}=40$ ] (Figure 3). The average operating time was 4.2 hours (range 3.8 to 6.3 hours) and the average blood loss was 1100 milliliters (range,750 to 2540 milliliters).

In 31 patients, the Ziehl-Neelsen stain was positive while culture of the organisms was positive in only 17 patients. This was possibly due to prolonged anti-tubercular chemotherapy prior to surgical intervention. Chemotherapeutic agents were administered by a standard protocol. Pediatric patients were administered a four-drug regime while adults received a five-drug regime. Streptomycin was routinely avoided in children. In adults, the usual dose of streptomycin varied from $750 \mathrm{mg}$ to $1000 \mathrm{mg}$ depending on the weight. It was given intramuscularly daily for a period of three months. The standard four-drug therapy included isoniazid $(5 \mathrm{mg} / \mathrm{kg})$, rifampicin (10 $\mathrm{mg} / \mathrm{kg})$, ethambutol $(15 \mathrm{mg} / \mathrm{kg}$ ) and pyrazinamide $(25 \mathrm{mg} / \mathrm{kg})$. These four drugs were administered for the first four months except pyrazinamide which was stopped after the first two months of therapy and a three-drug regime was administered for the next 8 months or longer until there was radiological and pathological evidence of regression of the disease. ${ }^{[3,14]}$

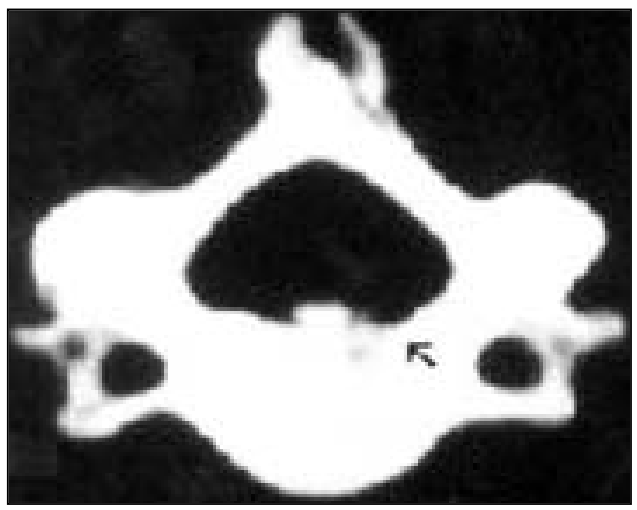

Figure 1b: Axial CT scan showing early subchondral destruction of the vertebra due to tuberculosis confirmed by histological examination (arrow)

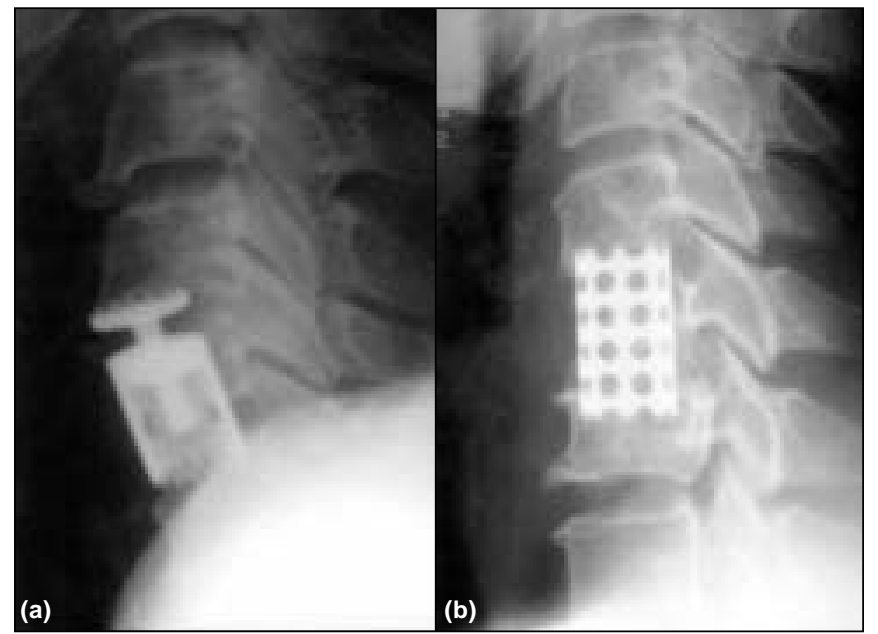

Figure 2: Plain radiographs of the lower cervical spine tuberculosis showing excision of the diseased vertebra followed by reconstruction with various types of titanium expandable cages and spacers 

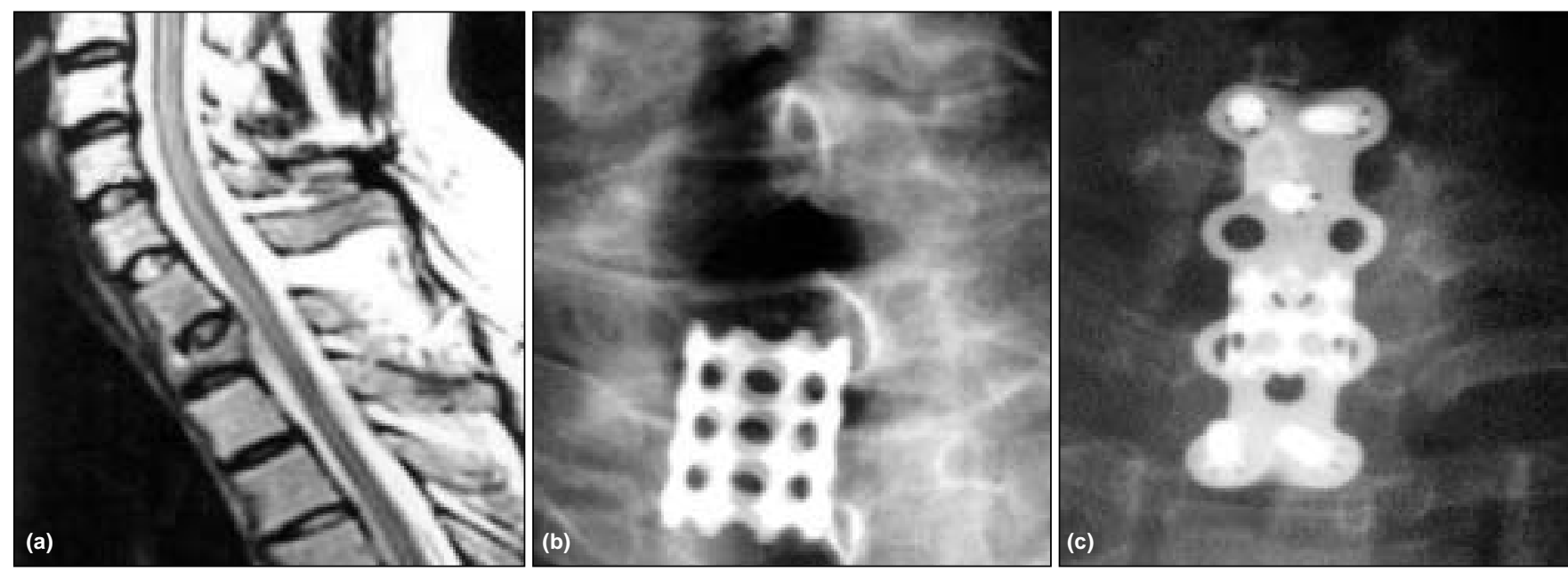

Figure 3: (a) Sagittal $T_{2}$-weighted MRI showing cervicodorsal region tuberculosis. (b) Plain radiograph showing D1 lesion treated with corpectomy and titanium spacer. (c) Plain radiograph showing D2 lesion treated with spacer and synthes plate with locking screws

Postoperatively, depending on the neurological functional level, the patients were mobilized as early as 24 hours after surgery. They were advised immobilization of the neck using a Philadelphia collar for 8 weeks and a soft collar for 8 more weeks. This regime leads to early mobilization, shortened hospital stay, low morbidity, rapid resolution of neurological symptoms and good patient satisfaction. Lateral and antero-posterior radiographs were obtained immediately following surgery, at 4 months and 1 year after surgery. Flexion/ extension radiographs were obtained at 24 months to assess fusion and any residual mobility. Patients were also advised against any excessive physical activity for a period of two years. The ESR was monitored for the presence of an active disease process.

\section{Results}

Success was defined as absence of pain, maintenance of spinal curvature and absence of motion in the fused segment at 24 months as demonstrated by flexion/extension radiographs. Neurological improvement was evaluated at each follow-up visit. All patients experienced marked reduction in pain and muscle spasm, which resulted in increased confidence level and physical activity. All patients demonstrated neurological improvement following surgery. The grade of improvement correlated directly with the severity of the preoperative symptoms. Three patients who had deltoid weakness had Grade V muscle power after surgery. The patient with C3 vertebra infection and monoplegia had Grade IV power in the upper limbs. All patients had regained fine movements, including writing and grasping. However, small muscle wasting in the hand did not recover completely and residual muscle wasting persists although without any motor sequelae. Sixteen patients with power of > Grade III, improved completely. However, nine patients with power of < Grade III typically had only a grade of improvement in their motor power. One patient with spastic paraplegia had improved to a point where he could walk a few steps with the support of a walker after 10 months but no further improvement was seen at 24 months. One patient with
D2 involvement and hoarseness of voice regained complete voice control at the end of 12 weeks. The results were classified as excellent [Grade V power at 1 year, $n=52(85 \%)$ ] good [residual wasting but no functional sequelae, $n=4(7 \%)$ ] and fair [persistent disability, $n=5(8 \%)]$. A satisfactory relief of pain and neurological improvement was seen in $92 \%$ patients in our series. The relief in pain without analgesics was assessed by a self-scored visual analog scale (1 minimum, 10 maximum). At the 4-month follow-up, the average score had improved from the preoperative score of 7 to 2 . No patient had any postoperative residual or recurrent angulation. Flexion/extension radiographs at 24 months showed good fusion and no mobility. There were no serious complications (Table 1). There was no relapse of the disease in any of our patients. The presence of pus, granulation tissue and thickening of tissues aids in dissection and prevents injury to the esophagus, major vessels or lung. Following good chemotherapy, there were no sequelae like draining sinuses, puckering of scar or deformity. There was no implant migration or malfunction. No implant required removal. Although observed in 21 patients in whom plates were not used, subsidence of the implant was not clinically significant in any patient in our series and was non-progressive (Figure 4). Postoperative difficulty in swallowing subsided within three to five days. In two patients the difficulty in swallowing lasted 8 and 10 days and improved spontaneously. One patient with hoarseness in voice improved in three weeks. Two patients with an indwelling urinary catheter developed infection and needed treatment.

Table 1: Complications during anterior reconstruction of the cervical spine for tuberculous infection

\section{Complication}

Dysphagia

Transient recurrent laryngeal nerve palsy

Subsidence of implant

Urinary tract infection

Deep vein thrombosis
Number $(n=61)$ 2

1

21

2 


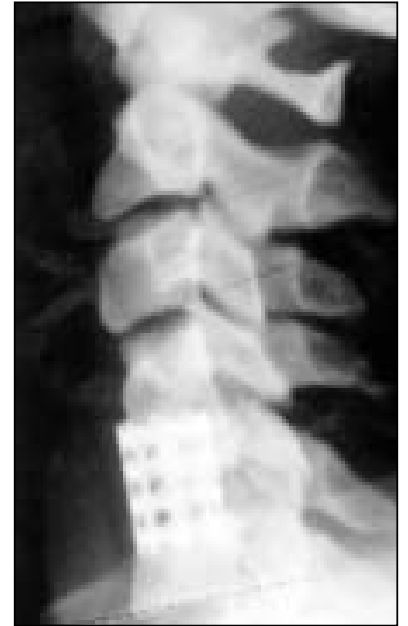

Figure 4: Plain lateral radiographs showing subsidence of implant without causing clinically significant deformity

One patient with deep vein thrombosis was treated with low molecular heparin.

\section{Discussion}

Spinal tuberculosis typically has an insidious onset and slow progression, although acute onset has been reported in the literature. ${ }^{[25]}$ Patients usually seek attention weeks to months after onset of the original symptoms due to the low intensity of the initial symptoms. The mean duration between onset of symptoms and clinical presentation in our series was 11.2 months (4-24 months). Mean averages of lesser durations have been reported in the literature. ${ }^{[9,10,12,14]}$ Constitutional symptoms like low fever, malaise, weight loss did not contribute to diagnosis in any patient in our series. These symptoms are more commonly seen with pulmonary or abdominal disseminated tuberculosis. No patient in our series was seropositive for Human Immunodeficiency Virus (HIV) infection. The incidence of tuberculosis is higher in immunocompromised patients $^{[26]}$ and there are reports in the literature describing surgical outcomes of spinal tuberculosis in HIV infected patients. ${ }^{[27]}$

In recent years, MRI has emerged as the premier modality to accurately image the spine. ${ }^{[25,28-34]}$ In our cohort of patients, it provided the earliest evidence of spinal tuberculosis. Infection (tuberculosis in endemic areas) typically reveals non-specific focal inflammatory bony changes of decreased $\mathrm{T}_{1}$ and high $\mathrm{T}_{2}$ signal intensity. MRI can distinguish the underlying mechanism of neurological compression by differentiating between bone and soft tissue lesions, which has a direct influence on the treatment policy. MRI can also distinguish the typical presentation from the atypical ones by imaging the intervertebral disc clearly. The involved intervertebral disc shows high $\mathrm{T}_{2}$ signal intensity as well as intense enhancement after gadolinium administration. MRI can also demonstrate unusual posterior neural arch involvement. ${ }^{[9,13,25,30]}$ In our se- ries, $33(54 \%)$ patients had some degree of neurological deficit. The deficit ranged from total spastic paraplegia with flexor spasms to early myelopathy with brisk jerks and radiculopathy in the upper extremities. The degree of motor affection ranged from weakness of handgrip to frank monoplegia in one patient with C3 vertebra lesion. The reported incidence of neurological deficit in cases of spinal tuberculosis varied from $23 \%$ to $76 \% .^{[7,9,10,12,14,15,35,36]}$ A typical Pott's spine presentation (involvement of two adjacent vertebrae, intervertebral disc and deformity) was seen less commonly (20\%) as compared to atypical presentations (involvement of one vertebra, bone destruction, instability). Patients with cervical spine tuberculosis typically present before development of severe kyphosis unlike patients with tuberculosis of thoracic spine. In our series, no patient had significant deformity. The main indication for surgery was to reverse the progressive neurological deficit and prevent kyphosis of the cervical spine. Residual neurological deficit is the worst complication of spinal tuberculosis. Early detection and correction of deformity leads to improvement of neurological deficit in $80 \%$ patients whereas a late correction is associated with only $20 \%$ improvement. ${ }^{[2]}$

There are a few cases reported about the use of posterior instrumentation for cervical tuberculosis but it is associated with increased morbidity and requires a double approach. ${ }^{[22,37,38,39]}$ It is also fraught with increased operating time, prolonged anesthesia and greater blood loss. Since the vertebral body lies anterior and is commonly affected in tuberculosis, decompression and stabilization has to be done by approaching the spine anteriorly ${ }^{[40]}$ Late onset neurological compression can be best avoided by preventing deformity. Patients who are treated conservatively have an average of 15degree kyphosis and $3 \%$ to $5 \%$ of these patients may end up with a deformity of greater than 60 degrees. This is particularly so in young patients in whom bone growth leads to worsening of the deformity. ${ }^{[1]}$ The lesions involving the vertebrae and pedicles of the cervical spine cause instability ${ }^{[41-44]}$ and need anterior instrumentation to stabilize the spine. The use of anterior instrumentation in thoracolumbar spine tuberculosis has been shown to be associated with a high fusion rate, low complication rate and increased correction rate in kyphosis.

The surgical approach to the cervicodorsal region and exposure of the lower cervical spine and the upper dorsal region is quite challenging. Sundaresan et $\mathrm{a}^{[45]}$ have described an approach to the upper two dorsal vertebrae, which includes resection of a portion of the clavicle and the manubrium sterni. A T-shaped skin incision is used, with the horizontal limb 1 $\mathrm{cm}$ above the clavicle, and the vertical limb extending in the midline over the body of the sternum. The avascular tissue plane between the carotid sheath laterally and the trachea and esophagus medially is developed to reach the prevertebral space. After surgery, immediate fusion is performed using the clavicle and manubrium. Immediate stabilization may also be 
achieved with methyl methacrylate replacement of the vertebral bodies, if necessary. The operation requires minimal postoperative immobilization. Sar et $\mathrm{l}^{[46]}$ have modified Sundaresan's technique. They did not damage the sternoclavicular joint. After decompression and fusion was completed, the osteotomized segment was replanted. They have successfully employed this technique in Pott's disease and reported no problem with union at the osteotomy sites. Lipskaia et $\mathrm{al}^{[47]}$ have described an approach to the cervicothoracic and upper thoracic spine for patients with tuberculous spondylitis from the fifth cervical vertebra to the ninth thoracic vertebra complicated by severe kyphotic deformity. It is carried out under visual guidance through the periscapular triangle by diverting the scapula cranially without dissecting its fixing muscles, the latissimus dorsi caudally. The third or fourth rib is resected in relation to the site of a pathological process. There is minimum trauma and the muscle integrity is preserved. A trans-sternal decompression following post laminectomy caries of the upper dorsal spine is also described. ${ }^{[4]}$

Neurological recovery following anterior surgical decompression and fusion is not always satisfactory with regard to deformity correction. ${ }^{[49-51]}$ The rate of graft failure due to fracture, migration, subsidence is alarming (59\%). The graft may also sink into the cancellous vertebral bodies causing exaggeration of kyphosis, especially in patients with involvement of two or more vertebrae with the graft length exceeding two or more disc spaces. Lifeso et $\mathrm{al}^{[50]}$ have reported an increase in the kyphotic deformity after anterior decompression by an average of 0.6 degree. Loembe et $\mathrm{l}^{[51]}$ have reported reduction of kyphosis in only four patients in a series of nine adult patients with cervical tuberculosis with cord compression treated by anterior debridement and fusion. There have been recent reports in the literature about the satisfactory results obtained in anterior fixation of the cervical spine in tuberculosis using plate and screws with resultant excellent correction of the kyphosis and a strong segmental stability. ${ }^{[5,52-61]}$ Yilmaz et a ${ }^{[5]}$ suggested in their study of 22 patients of spinal tuberculosis who had moderate to severe localized kyphosis that anterior instrumentation is more effective than posterior instrumentation for reducing the deformity and stabilization of the vertebral column. Faraj et al ${ }^{[57]}$ reported full neurological recovery at two to six years follow-up with no recurrence of disease or deformity in three adult patients with Frankel C quadriplegia due to cervical spine tuberculosis treated by debridement, grafting and plate fixation. Hassan et al ${ }^{[58]}$ reported $85 \%$ complete neurological recovery and improvement in kyphosis from 21.6 degrees to 2.5 degrees at the latest followup in their series of 16 patients with lower cervical spine tuberculosis treated with anterior debridement, fusion and $\mathrm{H}-$ plate fixation. Our experience in the surgical treatment of cervical spine tuberculosis before the use of anterior fusion with fixation was not encouraging. The present experience in a series of 61 consecutive patients of subaxial and cervicodorsal region spinal tuberculosis with anterior fixation with expandable cages, titanium spacers and plate with locking screws further enhances and reiterates the observations reported in recent series on this subject. The firm segmental fixation provided by the construct helps to prevent graft collapse and also prevents kyphotic deformity.

Modern chemotherapy has a significant impact on the natural progression and treatment outcomes in tuberculosis. Tuberculous infection can be completely cured with adequate treatment. Tubercular inflammation leads to increased vascularity, which stimulates a high rate of osteosynthesis once the infection is controlled. The optimal outcomes call for early and agrosessive decompression of neural tissue to enable it to recover completely. Surgery can be performed, as early as 24 hours after the initiation of chemotherapy, in patients with acute neurological compromise. The metallic implants do not hinder surgical outcomes. Surgical decompression of tuberculosis of the spine usually leads to some degree of neurological recovery irrespective of the severity of the presenting symptoms. One patient with spastic paraplegia and flexor spasms had gained enough strength to walk with the help of a walker without any spasms, at the end of 10 months although recovery reached a plateau by 24 months with no further improvement.

Deformity and neurological impairment are major residual problems of spinal tuberculosis after eradication of the infection. Anterior spinal instrumentation is needed to support the collapsed anterior weight-bearing column of the cervical spine. It has been confirmed clinically by studies showing that even in the presence of metallic foreign bodies, the disease responds well to antituberculous chemotherapy. In our experience, we have implanted patients with acute neurological compromise, as early as 24 hours after starting chemotherapy. None of the implants in the current series have failed or necessitated removal. Once the process of osteosynthesis has progressed well (4 months), the implants do not fail. ${ }^{[62]}$ None of the patients in this series developed significant deformity, the longest follow-up being six years. We consider anterior instrumentation with titanium implants a useful adjunct in reconstruction of the cervical spine that is affected by tuberculous infection. In view of our experience of subsidence of implants without plates, we now recommend use of cervical plates with locking screws in all cases. The important preventive or remedial countermeasures are proper selection of patients, meticulous preoperative preparation, proper selection of implants, standard and skillful manipulation and rational postoperative protection. ${ }^{[61]}$

\section{Conclusions}

Optimal evaluation of surgical strategy is mandatory in the management of cervical spine tuberculosis especially affecting the anterior column over more than one vertebra. In addi- 
tion to decompression of the neural tissue, anterior reconstruction using titanium implants is a useful adjunct for the prevention and correction of the deformity. A satisfactory segmental stability and fusion is achieved. The use of cervical plates with locking screws is recommended in all cases. Implants also spare the patient the added morbidity of the iliac crest autograft.

\section{References}

1. Rajasekaran S. The problem of deformity in spinal tuberculosis. Clin Orthop and Related Research 2002;398:85-92

2. Moon MS, Woo YK, Lee KS, Ha KY, Kim SS, Sun DH. Posterior instrumentation and anterior interbody fusion for tuberculous kyphosis of dorsal and lumbar spines. Spine 1995;20:1910-6.

3. Moon MS. Tuberculosis of the spine. Controversies and a new challenge. Spine 1997;22:1791-7.

4. Tureyen K. Tuberculoma of the conus medullaris. A case report. Neurosurgery 2003;50:651-3.

5. Yilmaz C, Selek HY, Gurkan I, Erdemli B, Korkusuz Z. Anterior instrumentation for the treatment of spinal tuberculosis. J Bone Joint Surg Am 1999;81:1261-7.

6. Fam AG, Rubenstein J. Another look at spinal tuberculosis. J Rheumatol 1993;20:1731-40.

7. Hayes A.J, Choksey M, Barnes N, Sparrow OC. Spinal tuberculosis in developed countries: Difficulties in diagnosis. J R Coll Surg Edinb 1996;41:192-6.

8. Buchelt M, Lack W, Kutschera HP, Katterschafka T, Kiss H, Schneider B, et al. Comparison of tuberculous and pyogenic spondylitis. An analysis of 122 cases. Clin Orthop 1993;296:192-9.

9. Colmenero JD, Jimenez-Mejias ME, Sanchez-Lora FJ, Reguera JM, PalominoNicas J, Martos F, et al. Pyogenic, tuberculous, and brucellar vertebral osteomyelitis: A descriptive and comparative study of 219 cases. Ann Rheum Dis 1997;56:709-15.

10. Cotten A, Flipo RM, Drouot MH, Maury F, Chastanet P, Duquesnoy B, et al. [Spinal tuberculosis. Study of clinical and radiological aspects from a series of 82 cases] J Radiol 1996;77:419-26. French.

11. Janssens JP, de Haller R. Spinal tubereulosis in a developed country. A review of 26 cases with special emphasis on abscesses and neurologic complications. Clin Orthop 1990;257:67-75.

12. Leibert E. Schluger NW, Bonk S, Rom WN. Spinal tuberculosis in patients with human immunodeficiency virus infection. Clinical presentation, therapy and outcome. Tuber Lung Dis 1996;77:329-34.

13. Lindahl S, Nyman RS, Brismar J, Hugosson C, Lundstedt C. Imaging of tuberculosis. IV. Spinal manifestations in 63 patients. Acta Radiol 1996;37:506-11.

14. Nussbaum ES, Rockswold GL, Bergman TA, Erickson DL, Seljeskog EL. Spinal tuberculosis: A diagnostic and management challenge. J Neurosurg $1995 ; 83: 243-7$.

15. Perronne C, Saba J, Behloul Z, Salmon-Ceron D, Leport C, Vilde JL, et al Pyogenic and tuberculous spondylodiskitis (vertebral osteomyelitis) in 80 adult patients. Clin Infect Dis 1994;19:746-50.

16. Rezai AR, Lee M, Cooper PR, Errico T.J, Koslow M. Modern management of spinal tuberculosis. Neurosurgery 1995;36:87-97.

17. Kostuik JP, Carl A, Ferron S. Anterior Zielke instrumentation for spinal deformity in adults. J Bone Joint Surg Am 1989;71:898-912.

18. Moskovich R, Benson D, Zhang ZH, Kabins M. Extracoelomic approach to the spine. J Bone Joint Surg Br 1993;75:886-93.

19. Chen W.J, Wu CC, Jung CH, Chen LH, Niu CC, Lai PL. Combined anterior and posterior surgeries in the treatment of spinal tuberculous spondylitis. Clin Orthop 2002;398:50-9.

20. Govender S. The outcome of allografts and anterior instrumentation in spinal tuberculosis. Clin Orthop 2002;398:60-6.

21. Mehta JS, Bhojraj SY. Tuberculosis of the thoracic spine. A classification based on the selection of surgical strategies. J. Bone Joint Surg Br 2001;83:859-63.

22. Mukhtar AM, Farghaly MM, Ahmed SH. Surgical treatment of thoracic and lumbar tuberculosis by anterior interbody fusion and posterior instrumentation. Med Prine Pract 2003;12:92-6.

23. Rath SA, Neff U, Schneider O, Richter HP. Neurosurgical management of thoracic and lumbar vertebral osteomyelitis and discitis in adults: A review of 43 consecutive surgically treated patients. Neurosurgery 1996;38:926-33.

24. Korkusuz F, Islam C, Korkusuz Z. Prevention of postoperative late kyphosis in Pott's disease by anterior decompression and intervertebral grafting. World J Surg 1997;21:524-8.
25. Maiuri F, Iaconetta G, Gallicchio B, Manto A, Briganti F. Spondylodiscitis Clinical and magnetic resonance diagnosis. Spine 1997;22:1741-6.

26. Bhojraj S, Nene A. Lumbar and lumbosacral tuberculous spondylodiscitis in adults. J Bone Jt Surg Br 2002;84:530-4.

27. Govender S, Parbhoo AH, Kumar KP, Annamalai K. Anterior spinal decompression in HIV-positive patients with tuberculosis. A prospective study. J Bone Joint Surg Br 2001;83:864-7.

28. Liu GC, Chou MS, Tsai TC, Lin SY, Shen YS. MR evaluation of tuberculous spondylitis. Acta Radiol 1993;34:554-8.

29. Ahmadi J, Bajaj A, Destian S, Segall HD, Zee CS. Spinal tuberculosis: Atypical observations at MR imaging. Radiology 1993;189:489-93.

30. al-Mulhim FA, Ibrahim EM, el-Hassan AY, Moharram HM. Magnetic resonance imaging of tuberculous spondylitis. Spine 1995;20:2287-92.

31. Desai SS. Early diagnosis of spinal tuberculosis by MRI. J Bone Joint Surg Br 1994;76:863-9.

32. Arizono T, Oga M, Shiota E, Honda K, Sugioka Y. Differentiation of vertebral osteomyelitis and tuberculous spondylitis by magnetic resonance imaging. Int Orthop 1995;19:319-22.

33. Kim N-H, Lee H-M, Suh JS. Magnetic resonance imaging for the diagnosis of tuberculous spondylitis. Spine 1994;19:2451-5.

34. Lanzieri C. Magnetic resonance imaging of infections of the spine. In: Haaga JR, Lanzieri CF, Gilkeson RC, editors. CT and MR imaging of the whole body. $4^{\text {th }}$ Ed. St. Louis: Missouri, EUA; 2003. p. 809-10.

35. Azzam NI, Tammawy M. Tuberculous spondylitis in adults. Diagnosis and treatment. Br J Neurosurg 1988;2:85-91.

36. Jain R, Sawhney S, Berry M. Computed tomography of certebral tuberculosis. Patterns of bone destruction. Clin Radiol 1993;47:196-9.

37. Guven O, Kumano K, Yalcin S, Karahan M, Tsuji S. A single stage posterior approach and rigid fixation for preventing kyphosis in the treatment of spinal tuberculosis. Spine 1994;19:1039-43.

38. Sundararaj GD, Behera S, Ravi V, Venkatesh K, Cherian VM, Lee V. Role of posterior stabilisation in the management of tuberculosis of the dorsal and lumbar spine. J Bone Joint Surg Br 2003;85:100-6.

39. Fuster S, Sala P, Prat S, Carles M.J, Colomer J, Suso S. Spinal tuberculosis: Early surgical treatment combined with medical treatment] Med Clin (Bare) 2001;117:457-9. [Article in Spanish]

40. Jain AK. Treatment of tuberculosis of the spine with neurological complications. Clin Orthop 2002;398:75-84

41. Tuli SM. Severe kyphotic deformity in tuberculosis of the spine. Int Orthop 1995;19:327-31.

42. Bhojraj SY, Shetty N, Shah PJ. Tuberculosis of the craniocervical junction. J Bone Joint Surg Br 2001;83:222-5.

43. Tuli SM. Tuberculosis of the craniovertebral region. Clin Orthop 1974;104:209-12.

44. Farage L, Martins JW, Farage FM. [Anterior instrumentation of spine in tuberculous spondylitis: Pott's disease: Arq Neuropsiquiatr 2002;60:142-4.

45. Sundaresan N, Shah J, Foley KM, Rosen G. An anterior surgical approach to the upper thoracic vertebrae. J Neurosurg 1984;61:686-90.

46. Sar C, Hamzaoglu A, Talu U, Domanic U. An anterior approach to the cervicothoracic junction of the spine (modified osteotomy of manubrium sterni and clavicle). J Spinal Disord 1999;12:102-6.

47. Lipskaia EA, Garbuz AE. [Surgical treatment of patients with cervicothoracic and upper thoracic spinal abnormalities] Probl Tuberk 1999;3:23-5. [Article in Russian]

48. Chatterjee S, Basu S. Trans-sternal decompression of postlaminectomy caries of the upper dorsal spine. Br J Neurosurg 2003;17:270-1.

49. Hsu LC, Leong JC. Tuberculosis of the lower cervical spine (C2 to C7). A report on 40 cases. J Bone Joint Surg Br 1984;66:1-5.

50. Lifeso RM, Weaver P, Harder EH. Tuberculous spondylitis in adults. J Bone Joint Surg Am 1985;67:1405-13.

51. Loembe PM, Mwanyombet-Ompounga L, Assengone-Zeh Y, KengueLechiombeka PR. [Early anterolateral surgery for tuberculosis of the lower cervical spine with neurological complications in adult. Our experience in Gabon] Neurochirurgie 2000;46:541-8. French.

52. Dharmalingam M. Tuberculosis of the spine-the Sabah experience. Epidemiology, treatment and results. Tuberculosis (Edinb) 2004;84:24-8.

53. Shi PH, Zhang J, Fan SW, Zhao K, Wan SL, Huang Y, et al. [Anterior instrumentation for the treatment of tuberculotic spinal deformity]. Zhonghua Wai Ke Za Zhi. 2003;41:292-5. [Article in Chinese]

54. Klockner C, Valencia R. Sagittal alignment after anterior debridement and fusion with or without additional posterior instrumentation in the treatment of pyogenic and tuberculous spondylodiscitis. Spine 2003;28:1036-42.

55. Benli IT, Kis M, Akalin S, Citak M, Kanevetei S, Duman E. The results of anterior radical debridement and anterior instrumentation in Pott's disease and comparison with other surgical techniques. Kobe J Med Sci 2000;46:39-68.

56. Benli IT, Acaroglu E, Akalin S, Kis M, Duman E, Un A. Anterior radical debridement and anterior instrumentation in tuberculosis spondylitis. Eur Spine 
J 2003;12:224-34

57. Faraj AA. Anterior instrumentation for the treatment of spinal tuberculosis. J Bone Joint Surg Am 2001;83:463-4.

58. Hassan MG. Anterior plating for lower cervical spine tuberculosis. Int Orthop $2003 ; 27: 73-7$.

59. Rao SC, Mou ZS, Hu YZ, Shen HX. The IVBF dual-blade plate and its applications. Spine 1991;16:S112-9.

60. Turgut M. Multifocal extensive spinal tuberculosis (Pott's disease) involving cervical, thoracic and lumbar vertebrae. Br J Neurosurg 2001;15:142-6.
61. Li L, Cui SQ, Wang H. [Clinical application of anterior cervical locking plate systems and analysis of complications as well as their countermeasures] Zhongguo Xiu Fu Chong Jian Wai Ke Za Zhi 2004;18:28-30. [Article in Chinese]

62. Oga M, Arizono T, Takasita M, Sugioka Y. Evaluation of the risk of instrumentation as a foreign body in spinal tuberculosis. Clinical and biologie study Spine 1993;18:1890-4.

Accepted on 21.07.2004.

\section{Invited Comments}

Ramani et al report their substantial experience with the management and outcome in 61 patients diagnosed with subaxial and cervicodorsal tuberculosis. Their strategy of ventral decompression of the neural elements and fusion with instrumentation has yielded good results in a large majority of their patients who experienced relief of the two main symptoms of pain and neurological dysfunction. Their series is unique for the high incidence $(80 \%)$ of atypical radiological presentation (lack of involvement of the disc space) and the zero incidence of kyphotic deformity of the cervical spine. However, in some of the illustrations a mild kyphotic change is evident both at the involved segments and of the whole cervical spine. The authors do not mention whether any bone graft was used to fill in the defects created by the removal of the diseased bony and disc elements in their plated group of patients (40 patients). One would definitely consider using a bone graft to achieve early fusion and maintain cervical lordosis. To support the authors' contention that none of their patients developed any "clinically significant" kyphotic change in the cervical spine curvature, they should have provided quantitative data in the form of Cobb angles of the involved segments on the preoperative and follow-up radiographs. The sagittal alignment of the cervical spine could also have been assessed (as lordotic, straight or kyphotic) on the preoperative and follow-up radiographs. It is also unfortunate that there are no illustrations of the sagittal alignment of the cervical spine in the plated group of patients. Ventral bony fusion of the cervical spine is almost always associated with some degree of settling of the bodies leading to a variable degree of change in the sagittal alignment of the cervical spine both segmentally and globally. ${ }^{[1]}$ Admittedly, this change in the cer- vical spine curvature is not clinically relevant in the shortterm but may have a bearing on the long-term outcome of these patients in the form of adjacent segment spondylotic changes and neck pain. Results similar to those reported by the authors have been reported by us recently, ${ }^{[2]}$ albeit, in a smaller cohort of patients with subaxial cervical spine tuberculosis. Our surgical strategy, which was also directed ventrally, differed from that of the authors in the avoidance of instrumentation but in exchange for bed rest for 4 to 6 weeks following surgery. Use of a halo-vest following uninstrumented ventral decompression and fusion would be an alternative strategy. One of the major advantages of uninstrumented surgery is the ability to limit the vertical height of the corpectomy to only the involved parts of the vertebrae as even as little as a third of the normal vertebral body is adequate to create a mortice to accept the bone graft. Besides this, cost reduction is also a major consideration in this patient population which is generally from the economically deprived sections of society.

\section{Rajshekhar}

\section{Christian Medical College, Vellore, Tamil Nadu, India} E-mail: rajshekhar@cmcvellore.ac.in

\section{References}

1. Rajshekhar V, Arunkumar M.J, Kumar SS. Changes in cervical spine curvature after uninstrumented one- and two-level corpectomy in patients with spondylotic myelopathy. Neurosurgery 2003;52:799-805.

2. Moorthy RK, Arunkumar M.J, Rajshekhar V. Uninstrumented ventral surgery for subaxial cervical spine tuberculosis: Clinical and radiological outcome. $\mathrm{Br}$ J Neurosurg 2004;18:584-9. 